\title{
GERMINAÇÃO DE SEMENTES DE MAÇÃ (1)
}

Fernando A. Campo dall'Orto (2), Mário Ojima $\left(^{2}\right)$ e Orlando Rigitano, Seção de Fruticultura de Clima Temperado, Hélio J. SCARANARI $\left(^{2}\right)$ e FERNANDo P. MARTINs $\left(^{2}\right)$, Estação Experimental de Jundiaí, Instituto Agronômico

\section{SINOPSE}

Efetuaram-se em Campinas, SP, dois experimentos, procurando conhecer peculiaridades da germinação de sementes de maçā, de acordo com os cultivares e os processos de preparo.

No primeiro, sementes de 30 cultivares foram estratificadas em substrato úmido e a baixa temperatura $\left(5-10^{\circ} \mathrm{C}\right)$, para a quebra de dormência. De modo geral, as porcentagens de germinação foram bastante elevadas, sendo que 26 daqueles cuitivares apresentaram-se com mais de $93 \%$. No entanto, os cultivares estudados mostraram sensiveis variaçōes quanto à velocidade de germinação; no ambiente de estratificação, a germinação teve início por volta do terceiro mês, continuou rapidamente no quarto e quinto, completando-se no sexto mês.

No segundo experimento, sementes de três cultivares locais foram extraídas de frutos armazenados em ambiente de laboratório e em câmara frigorífica, durante diferentes períodos de tempo, e semeadas imediatamente ou depois de 90 dias de estratificaçẵo a frio. Naquelas extraídas de frutos mantidos ao ambiente, as porcentagens de germinação decresceram com o aumento do tempo de armazenamento, provavelmente devido aos efeitos perniciosos da deterioração da polpa. Os melhores resultados foram obtidos com sementes extraídas de frutos recém-colhidos e semeadas após um periodo de estratificação a frio úmido. Sementes extraídas de frutos conservados no frigorífico e semeadas após estratificação, exibiram também altas porcentagens de germinação.

\section{1 - INTRODUÇÃO}

$\mathrm{Na}$ plantação de um pomar comercial de macieira, a prática comum é lançar mão de mudas enxertadas; o porta-enxerto tradicionalmente empregado é a própria macieira prove- niente de semente de variedades rústicas, o qual, por via de regra, resulta na formação de árvores de grande porte, exigentes de amplo espaçamento.

(1) Recebido para publicação em 21 de dezembro de 1977.

(2) Com bolsa de suplementação do C.N.Pq. 
No Estado de São Paulo, todavia, o porta-enxerto mais utilizado provém de estacas enraizadas de várias linhagens da variedade docinha — Doucin dos franceses ou Dolcino dos italianos - tipo de maçã de procedência européia, de frutos pequenos, amarelos e bastante doces, que se multiplica vegetativamente com facilidade, e que propicia a formação de árvores de porte mediano. $O$ processo usual de obtenção desse porta-enxerto é o de "amontoa-de-cepa", em viveiros de plantas matrizes.

Por outro lado, nos principais países produtores de maçã, verifica-se ultimamente uma tendência crescente para se formarem culturas intensivas, utilizando seleções de porta-enxerto de propagação vegetativa, capazes de induzir à planta características ananicantes. As macieiras enxertadas sobre tais porta-enxertos, mesmo adultas, são de pequeno porte, permitindo o uso de espaçamentos menores entre as plantas, originando, assim, pomares mais densos, de mais fácil manejo, produção mais precoce e, o que é mais importante, de maior produtividade do que as plantações tradicionais.

Tem-se destacado na seleção desse tipo de porta-enxerto para macieira, a East Malling Research Station, na Inglaterra, onde tiveram origem os conhecidos clones das séries de prefixos EM (East Malling) e MM (Malling-Merton). Entre os primeiros destacam-se: EM IX e EM 26, como tipos anões; EM IV e EM VII, semi-anões; EM II (Doucin de Fontenay, semelhante à docinha-de-valinhos), medianamente vigoroso. Entre os últimos, que se caracterizam pela resistência ao pulgão lanigero, destacam-se: MM 106, semi-anão; MM 104 e MM 111, medianamente vigorosos; MM 109, vigoroso. Entre nós, alguns desses porta-enxertos estão sendo observados experimentalmente no Instituto Agronômico do Estado de São Paulo, e já vêm sendo utilizados em culturas comerciais recentemente plantadas em Santa Catarina.

Não obstante o grande interesse existente em relação ao uso de porta-enxertos de origem clonal, pés francos de macieira, ou seja, macieiras obtidas de sementes, ainda são os porta-enxertos mais difundidos nas tradicionais regiões mundiais produtoras de maçãs. Nos Estados Unidos, a maioria dos pomares antigos está enxertada sobre "seedlings" de French Crab, tipo de macieira rústica, cujas sementes são importadas da França como subprodutos das indústrias de sidra (1). São comuns, também, em todos os países onde se cultiva a macieira, pomares comerciais que utilizam como porta-enxertos "seedlings" das principais variedades existentes nas culturas locais.

Os porta-enxertos provenientes de sementes oferecem vantagens $e$ desvantagens. Como principais vantagens citam-se: a facilidade de obtenção de material local para multiplicação; a formação de plantas rústicas, longevas, com sistema radicular amplo, profundo, livres de viroses e de grande adaptabilidade a diferentes típōs đe solo. Por outro lado, são seus incovenientes: a falta de uniformidade no desenvolvimento das plantas, deyido à heterogeneidade genética do material; o vigor excessivo que induz à formação de árvores de grande porte, de manejo difícil e exigentes de largo espaçamento; além disso, os pomares demoram em iniciar a fru- 
tificação e a produtividade é menor que a das culturas intensivas.

A importância que vem adquirindo nos últimos anos a cultura da maçã no Estado de São Paulo justifica, assim, a necessidade de que se realizem pesquisas básicas, para a escolha dos porta-enxertos mais adequados às condições locais.

A esse respeito, não resta dúvida que os estudos de germinação de sementes de maçã constituem o ponto de partida para se colher as informações preliminares indispensáveis a esse objetivo. Elas fornecerão esclarecimentos sobre os métodos mais eficientes de preparo das sementes $\mathrm{e}$ sobre a capacidade de reprodução dos cultivares atualmente disponíveis no Estado. Esses estudos proporcionarão, também, os "seedlings" a serem pesquisados em seu comportamento, como porta-enxertos, ou como plantas matrizes de novos porta-enxertos, especialmente selecionados para o ambiente local, a exemplo do que vem sendo feito com a pereira (2).

$\mathrm{N}$ e s s e sentido, conduziram-se dois experimentos de germinação, na Seção de Fruticultura de Clima Temperado, do Instituto Agronômico do Estado de São Paulo, cujos resultados são aqui relatados.

\section{2- MATERIAL E METODOS}

\section{1 - GERMINAÇÃO EM RELAÇÃo AOS CULTIVARES}

Colheram-se, em fevereiro de 1976, frutos maduros e sadios de 30 cultivares de macieira, constantes da coleção do Instituto Agronômico, na Estação Experimental de Jundiaí.
Depois de anotado o número de frutos colhidos por cultivar, fez-se a extração das sementes que foram imediatamente levadas, contadas em amostras de 100 , pesadas e tratadas com solução de Thiran a $0,2 \%$.

Para se obter, pelo menos, 100 sementes por cultivar, o menor número de frutos utilizados foi 30 , em pedra branca e primasia, e o maior, 214, em IAC 7-18, numa média de 86 frutos por cultivar.

As sementes foram separadas em duas parcelas de 50 por cultivar, e depois de estratificadas em placas de petri tendo algodão umedecido como substrato, foram colocadas em câmara frigorífica, a $5-10^{\circ} \mathrm{C}$, em 24/2/76.

As placas de petri permaneceram constantemente fechadas, a fim de assegurar adequado teor de umidade às sementes. Nesse ambiente de frio úmido, o início da germinação aconteceu cerca de 90 dias após, e aos 180 dias, a maioria das sementes havia germinado. As que não germinaram já haviam deteriorado ou permanecido "duras", sem condições de germinação., Desse modo, depois de anotado mensalmente durante seis meses, o número de sementes germinadas, foi dada por encerrada a experiência. Os "seedlings" obtidos foram mensalmente transplantados para o canteiro, sob ripado.

\section{2 - GERMINAÇÃO EM RELAÇÃO AO PREPARO DAS SEMENTES}

Para o estudo de processos de preparo das sementes de maçã foram colhidos, em 17/2/1976, frutos maduros, uniformes e sadios de três cultivares - rainha (IAC 8-31), dulcina (IAC 8-35) e culinária (IAC 
5-10) - da coleção de variedades e híbridos, na Estação Experimental de Jundiaí, do Instituto Agronômico do Estado de São Paulo.

Adotaram-se os seguintes tratamentos: A) extração e semeadura imediatas; B) extração imediata das sementes e semeadura após estratificação e frio; C, D, E e F) extração das sementes após $15,30,45$ e 60 dias, respectivamente, de frutos conseryados ao ambiente de laboratório, e semeadura após estratificação a frio; G) extração das sementes de frutos conservados no frigorífico, a $5-10^{\circ} \mathrm{C}$, por 60 dias, e semeadura imediata; H) extração das sementes de frutos conservados no frigorífico, por 60 dias, e semeadura após estratificação a frio.

$\mathrm{O}$ experimento teve início em $20 / 2 / 1976$, utilizando-se, por tratamento e por cultivar, 80 frutos, divididos em dois lotes de 40. À exceção dos tratamentos de extração imediata das sementes (Tratamentos A e B), cada lote foi colocado, separadamente, em recipiente de plástico, mantido aberto, durante o período de conservação.

De acordo com a especificação de cada tratamento, as sementes foram sendo cuidadosamente extraídas, lavadas em água corrente e postas a secar à sombra, à exceção daquelas referentes à extração imediata. De cada lote foi separada amostra de $\mathbf{5 0}$ sementes, para constituir a parcela experimental.

As sementes referentes aos tratamentos A e G, foram semeadas em canteiros de terra, sob ripado, em $23 / 2 / 1976$ e $20 / 4 / 1976$, respectivamente, logo após terem sido extraídas dos frutos. As demais foram sendo extraídas nas épocas estabelecidas e conservadas em saco de papel-manteiga, até a estratificação, realizada em 20/4/1976.

Para a estratificação foram utilizadas, por tratamento e cultivar, duas placas de petri, colocando-se em cada uma, 50 sementes referentes à parcela experimental, tendo algodão umedecido como substrato, e mantendo-as fechadas em câmara frigorífica a $5-10^{\circ} \mathrm{C}$. Antes da estratificação, as sementes foram previamente imersas em água, por 24 horas e, em seguida, tratadas com solução de Thiran a $0,2 \%$.

Em 20/7/1976, depois de três meses de estratificação, foi feito o primeiro controle dos resultados de germinação, ainda nạ geladeira. Procedeu-se em seguida, à semeadura de todo o material germinado e por germinar - em canteiro de terra, sob ripado.

Em 20/9/1976, transcorridos dois meses da semeadura, fez-se nova leitura da germinação, dando-se por encerrada a experiência.

\section{3 - RESULTADOS E DISCUSSĀO}

\section{1 - GERMINAÇĀo EM RELAÇÃo AOS CULTIVARES}

Os resultados mensais de germinação, por cultivar, encontram-se reunidos no quadro 1 . Nesse quadro, estão também anotados $o$ número médio de sementes por fruto e o peso de 100 sementes.

Nos 30 cultivares estudados não se observou grande variação nos índices finais de germinação, ao sexto mês de controle, pois em dez dos trinta cultivares $o$ índice de ger- 
\&

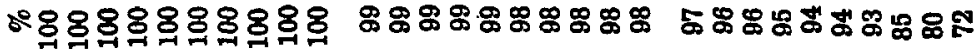

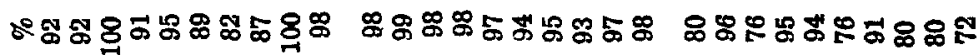

1

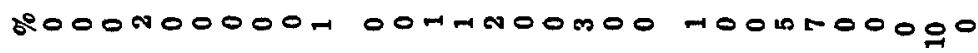

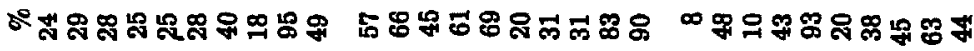

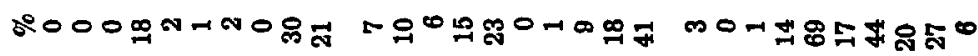

s000-1000000

0०न-700न00

OOOHNOOONO

0

幽

要

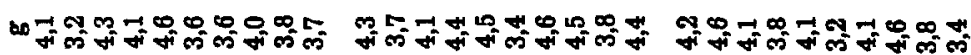

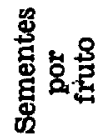

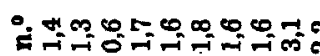

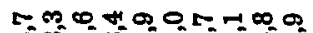

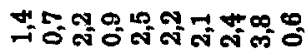

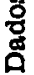


minação foi $100 \%$, e apenas seis germinaram menos que $95 \%$. Observaram-se, porém, sensíveis diferenças entre os cultivares, quanto à velocidade de germinação, com base nas leituras mensais efetuadas durante os seis meses de duração do experimento. Em alguns deles, a germinação iniciou mais tarde, no quarte mês, completando-se, rapidamente, em período mais curto, enquanto em outros, o início da germinação ocorreu mais cedo, no terceiro mês, completando-se gradativamente, até o sextó mês.

Tendo em vista que a germinação constatada foi alta praticamente em todos os cultivares, poderá haver conveniência em se eleger para a produção de "seedlings" aqueles que apresentarem maior rendimento em número de sementes por fruto. Sob esse aspecto, destacaram-se os cultivares primasia, starking, favorita, pedra branca, rome beauty, artic $\mathrm{e}$ winter banana, com mais de três sementes por fruto. No outro extremo, situaram-se os cultivares paulista (IAC 6-3), IAC 7-18, glengyle red e red astrakan, com média inferior a uma semente por fruto. Naturalmente, outros fatores mais importantes deverão ser considerados também, para a eleição dos melhores cultivares para porta-enxertos.

Em observações anteriores realizadas no IAC quando da obtenção de porta-enxertos através de sementes, a variedade primasia tem-se destacado das demais, especialmente pelo melhor desenvolvimento vegetativo de seus "seedlings". Por sua vez, no presente trabalho, o cultivar dulcina (IAC 8-35), descendente direto de primasia, apresentou satisfatória capacidade para formar sementes de bom poder germinativo, e seus "seedlings" também vêm mostrando crescimento vigoroso e uniforme; por se tratar de um novo cultivar que apresenta elevada produtividade em nosso meio, presume-se que possa tornar-se uma fonte de sementes, para a obtenção de porta-enxertos vigorosos para as nossas condições.

\section{2 - GERMTNAÇÃO EM RELAÇÃO AO PREPARO DAS SEMENTES}

No quadro 2 acham-se reunidos os dados sucessivos de germinação, iniciada no frigorífico, e continuada em canteiros de terra, sob ripado, referentes a três cultivares, em oito tratamentos de preparo de sementes.

Os resultados obtidos mostram diferenças sensiveis na germinação, dependendo do método de preparo adotado. Verificou-se que a germinação manteve-se satisfatória - acima de $60 \%$ - quando as sementes foram extraídas de frutos conservados até 30 dias depois da colheita em ambiente natural, e estratificadas, em seguida, em ambiente frio. A.deterioração progressiva da polpa dos frutos maduros conservados ao ambiente, parece afetar, cada vez mais, a viabilidade das sementes, como já se verificou, em nossas condições, com sementes de pêssego e caqui $(3,4)$. Assim, o preparo das sementes mediante extração imediata e estratificação a frio resultou em alto indice de germinação: $91,7 \%$; depois esse índice baixou para 77,7\% e $61,7 \%$, quando os frutos conservados, respectivamente, por 15 e 30 dias, e diminuindo ainda mais, quando as sementes foram extraídas de frutos conservados por 45 e 60 dias, respectivamente: 15,3 e $13,0 \%$ de germinação. 
QUADRO 2. - Porcentagens de germinação de três cultivares de macieira, sob oito tratamentos de preparo de sementes

\begin{tabular}{|c|c|c|c|c|}
\hline \multirow{2}{*}{ TRATAMENTO } & \multicolumn{3}{|c|}{ Germinação ( $\left.{ }^{1}\right)$} & \multirow{2}{*}{ Média } \\
\hline & Rainha & Dulcina & Culinária & \\
\hline & $\%$ & $\%$ & $\%$ & $\%$ \\
\hline A - Extraçāo e semeadura imediatas & 1 & 13 & 2 & 5,3 \\
\hline $\begin{array}{l}\text { A - Extração imediata e estratifica- } \\
\text { ção a frio }\end{array}$ & $90(23)$ & $94(43)$ & $91(14)$ & 91,7 \\
\hline $\begin{array}{l}\text { C - Extração após } 15 \text { dias e estrati- } \\
\text { ficação a frio }\end{array}$ & $77(13)$ & $83(26)$ & $73(15)$ & 77,7 \\
\hline $\begin{array}{l}\text { D - Extração após } 30 \text { dias e estrati- } \\
\text { ficação a frio }\end{array}$ & $52(6)$ & $70(38)$ & $57(20)$ & 61,7 \\
\hline $\begin{array}{l}\text { E - Extração após } 45 \text { dias e estrati- } \\
\text { ficação a frio }\end{array}$ & $24(8)$ & $16(5)$ & $6(0)$ & 15,3 \\
\hline $\begin{array}{l}\text { F - Extração após } 60 \text { dias e estrati- } \\
\text { ficação a frio }\end{array}$ & $14(8)$ & $12(3)$ & $13(3)$ & 13,0 \\
\hline $\begin{array}{l}\text { G - Extração após } 60 \text { dias, de frutos } \\
\text { conservados em geladeira e se- } \\
\text { meadura imediata }\end{array}$ & 13 & 21 & 14 & 16,0 \\
\hline $\begin{array}{l}\text { H - Extraçāo após } 60 \text { dias, de frutos } \\
\text { conservados em geladeira e estra- } \\
\text { tificação a frio }\end{array}$ & $83(49)$ & $89(80)$ & $90(53)$ & 87,3 \\
\hline
\end{tabular}

(1) Os números entre parêntesis referem-se às porcentagens de germinação inicial, ainda na geladeira, nas placas de petri, antes da semeadura no canteiro.

Como era de se esperar, as sementes extraídas de frutos conservados em perfeitas condições - sob refrigeração a $5-10^{\circ} \mathrm{C}$, por 60 dias - e submetidas à estratificação a frio apresentaram boa germinação: 87,3\%. Além disso, a germinação verificada durante o período de estratificação foi sensivelmente melhor que a dos demais tratamentos, chegando a atingir o índice de $80,0 \%$ no cultivar dulcina. Por outro lado, as sementes extraídas de frutos conservados por 60 dias em geladeira e semeadas sem estratificação mostraram germinação baixa: $16,0 \%$, ainda assim, pouco maior que aquela das sementes de frutos recém-colhidos e igualmente não estratificadas. $\mathrm{O}$ resultado desses dois tratamentos sugere que a exigência de frio para a quebra da "dormência" das sementes foi satisfeita, pelo menos em parte, enquanto elas se achavam no interior dos frutos conservados em câmara frigorífica.

\section{4 - CONCLUSÕES}

Os resultados dos dois experimentos permitiram chegar às seguintes conclusões:

a) Verificaram-se acentuadas diferenças no número de sementes por 
fruto e no peso de 100 sementes, nos 30 cultivares de macieira estudados. O número médio de sementes por fruto variou entre um mínimo de 0,6 e um máximo de 3,9 , enquanto que o peso de 100 sementes variou entre 3,2 e $4,6 \mathrm{~g}$.

A porcentagem de germinação na maioria dos 30 cultivares considerados foi bastante alta, sem grandes variações; apenas 6 mostraram índice inferior a $95 \%$.

Para a maioria dos cultivares estudados, a germinação praticamente iniciou no terceiro mês, intensificando-se acentuadamente no quarto e no quinto, para completar-se, finalmente, no sexto mês.

b) No preparo das sementes, os tratamentos em que se fez a estratificação a frio das sementes extraídas dos frutos, imediatamente e após 15, 30,45 e 60 dias, respectivamente apresentaram porcentagens decrescentes de germinação: $91,7,77,7$, $61,7,15,3$ e $13,0 \%$. Nos três me-
Ihores tratamentos - extração até 30 dias - o cultivar dulcina apresentou os índices de germinação mais elevados, respectivamente 94,83 e $76 \%$.

Sementes extraídas de frutos conservados em frigorífico, por 60 dias, e estratificadas a frio mostraram boa porcentagem de germinação: $87,3 \%$. Esse resultado é bastante superior àqueles apresentados pelos demais tratamentos, exceto aquele da extração imediata com estratificação a frio.

Em síntese, pode-se concluir que a demora na extração das sementes e a falta de estratificação a frio resultaram em baixas porcentagens de germinação. De um lado, confirmou-se que a estratificação a frio é indispensável à quebra da "dormên"cia" das sementes. De outro, constatou-se que a viabilidade das sementes de maçã diminui rapidamente, à medida que a polpa dos frutos se deteriora.

\section{GERMINATION OF APPLE SEEDS}

\section{SUMMARY}

Two experiments were performed to study the seed germination of several apple varieties at the Instituto Agronômico de Campinas, SP, Brazil.

In the first of the experiments seeds of 30 apple cultivars were collected from ripe fruits and maintained stratified in moist substractum in cold storage $\left(5-10^{\circ} \mathrm{C}\right)$ to break dormancy. Twenty six out of the 30 varieties tested showed germination over 93\%. The germination had started in the third month, while the seeds were still in the refrigerator, continued rapidly during the fourth and fifth months, and was completed at the sixth month.

In the second trial seeds of three local apple cultivars were collected from ripe fruits, kept in various storage conditions, and sowed immediately or after 90 days stratification period in cold storage. Those seeds extracted from ripe fruits maintained at lab ambiental conditions by different periods, showed decrescent germination indexes, probably due to the pernicious effect of pulp deterioration. The best results were obtained when the seeds were extracted immediately and sowed after a period of stratification to break dormancy. Seeds collected from fruits kept in cold storage and sowed after cold stratification showed also high germination percentage. 


\section{LFTERATURA CTTADA}

1. HANSEN, C. J. \& HARTMANN, H. T. Propagation of temperate-zone fruit plants. California Agr. Exp. Sta., 1958. 51 p. (Circular 471)

2. OJIMA, M. \& RIGITANO, O. Resultados preliminares da seleção de clones para porta-enxertos de pereira, visando boa capacidade de propagação vegetativa. Bragantia 29:287-292, 1970.

3. - ; CAMPO DALL'ORTO, F. A. \& RIGITANO, O. Sementes de pessego. Influência dos métodos de preparo na germinação das sementes de pêssego. Campinas, Instituto Agronômico, 1976. 7 p. (Circular 48)

4. - 